\title{
Importance of dispersal for the expansion of a Eurasian lynx Lynx lynx population in a fragmented landscape
}

\author{
Fridolin Zimmermann, Christine Breitenmoser-Würsten and Urs Breitenmoser
}

\begin{abstract}
Dispersal allows recolonization of previous areas of habitat following severe depression of a population but the significance of this is not clear in felids. There is little evidence to support the general belief that subadult felids will colonize new areas, although this is a crucial assumption in reintroduction or recovery projects. Eurasian lynx Lynx lynx were reintroduced into the Swiss Alps and have subsequently spread over part of their potential range but the expansion halted in the mid 1980s. We postulated that high lynx densities would lead to an expansion of the population, and to assess the potential of this population to expand we compared the dispersal characteristics of 22 subadults from the northwest Swiss Alps, where an increase in lynx abundance occurred from 1995 onwards, to 17 individuals from the Jura Mountains, an area with a lower lynx density.
\end{abstract}

Dispersal data came mainly from radio-telemetry. Dispersal rates and distances for subadults that completed dispersal were lower in the north-west Swiss Alps than in the Jura Mountains. In general, subadults exhibited little ability to cross major barriers such as highways. The hypothesis that high density alone will foster the expansion of the population was therefore not confirmed. This has consequences for the reintroduction and recovery of carnivores in fragmented landscapes. To establish only one strong source population may not be an optimal strategy, and population nuclei should therefore be founded in several neighbouring patches.

Keywords Density dependence, dispersal, fragmented landscape, Lynx lynx, population expansion, Switzerland.

\section{Introduction}

Natal dispersal, the movement of subadult animals from their natal range to the place where they will breed (Howard, 1960), is an important mechanism in the colonization of new areas. Individuals compete for local resources, and dispersers need to obtain access to unexploited resources. In a saturated population such resources are at the edge of or outside the colonized area. Hence, dispersal regulates abundance by expanding distribution (Dieckmann et al., 1999). Dispersal also allows recolonization of former habitats after a population decrease (Lubina \& Levin, 1988), and this is occurring in large carnivores in Europe and North America. Brown bears Ursus arctos, nearly extinct in the early 20th century, have recolonized large parts of

Fridolin Zimmermann* (Corresponding author) Department of Ecology and Evolution, University of Lausanne, Dorigny, $\mathrm{CH}-1015$ Lausanne, Switzerland. E-mail f.zimmermann@kora.ch

Christine Breitenmoser-Würsten KORA, Thunstrasse 31, CH-3074 Muri, Switzerland.

Urs Breitenmoser Institute of Veterinary Virology, University of Bern, Längassstrasse 122, CH-3012 Bern, Switzerland.

${ }^{*}$ Current address: KORA, Thunstrasse 31, CH-3074 Muri, Switzerland.

Received 12 July 2005. Revision requested 19 October 2005

Accepted 30 March 2006
Scandinavia (Swenson et al., 1995). The range outside the core areas was occupied by young bears, predominantly by males 2-4 years old, the age of most active dispersal (Swenson et al., 1998). Wolves Canis lupus from the Italian Apennine population recolonized the Alps, where the species had been eradicated in the 19th century (Breitenmoser, 1998). Recolonization of former range by dispersing wolves has also been observed in Minnesota (male-biased; Mech, 1987) and in the central Rocky Mountains (both sexes; Boyd \& Pletscher, 1999).

The significance of dispersal for the spread of a population is less clear in felids. Long-range dispersal has been described in Eurasian lynx Lynx lynx (J. Linnell, pers. comm.), in Canadian lynx Lynx canadensis (reviewed in Mowat et al., 2000) and in puma Puma concolor (Sweanor et al., 2000) but these were animals dispersing between or within extant populations. There is little evidence that dispersing subadult felids will colonize new territory, although this is a crucial assumption in reintroduction or recovery projects.

Eurasian lynx were reintroduced into the Swiss Alps in the early 1970s and have subsequently spread over the north-west of the Alpine arc (Breitenmoser et al., 1998). The expansion slowed down in the mid 1980s, despite the availability of suitable unoccupied habitat, and in the 1990s little or no evidence for lynx presence 
was found in some regions that had been previously colonized (Molinari-Jobin et al., 2001). After 1995 an increase in lynx abundance in the north-west Swiss Alps resulted in a controversy about the return of this species. Hunters, sheep breeders and the regional authorities demanded that the lynx population in this area be reduced (Breitenmoser et al., 1999). Such permission was, however, not given at that time, as the policy of the Federal Office for the Environment was to have lynx distributed throughout the Alps, and there was a general belief that the population pressure in the north-west Swiss Alps would further the expansion of the population.

The hypothesis that population pressure will result in an expansion of the occupied area (Hell, 1961) implies two assumptions: the population expands through natal dispersal, and dispersal is positively density dependent. Therefore both the rate and the mean distance of dispersal are greater when lynx are abundant. These assumptions have consequences for the colonization of new or former areas, and hence for the design of reintroduction projects. Furthermore, the nature of any dispersal is determined by resource availability, landscape (habitat and topography), and the social structure of the species. To assess dispersal in the north-west Swiss Alps during a period of peak lynx density (1.4-1.5 resident lynx per $100 \mathrm{~km}^{2}$; Breitenmoser-Würsten et al., 2001) we compared it with data from an earlier, similar study (Zimmermann, 1998) in the Jura Mountains where lynx density was low to average (0.7-0.8 resident lynx per $100 \mathrm{~km}^{2}$; Breitenmoser-Würsten et al., in press). To assess the potential of the population of the north-west Swiss Alps to expand we examined the dispersal rates, distances, directions, habitat and linear barriers crossed by dispersers compared to the Jura Mountains and postulated that (1) rate and distance of dispersal should be greater in the higher density population, and (2) most subadults would leave the north-west Swiss Alps and settle in neighbouring areas. Hence we assumed that the monitoring system for lynx in Switzerland (Capt et al., 1998) would reveal an increase of lynx presence, after a time lag, in the areas adjacent to the north-west Swiss Alps.

\section{Materials and Methods}

\section{Study Areas}

The north-west Swiss Alps are a $2,800 \mathrm{~km}^{2}$ area more or less isolated from the rest of the Alps and fragmented both by natural and artificial barriers (for details see Zimmermann, 2004; Fig. 1). Roe deer Capreolus capreolus, lynx's main prey (Breitenmoser \& Haller, 1987), were locally depressed during the peak of lynx density at the end of the 1990s. The number of roe deer harvested per $1 \mathrm{~km}^{2}$ forest, assumed to reflect roe deer abundance, has continuously decreased in the north-west Swiss Alps since 1994 (Fig. 2). The overall resident lynx density in the north-west Swiss Alps, based on the distribution of radio-collared animals and information about additional, untagged individuals from camera-trapping, was estimated at $1.4-1.5$ per $100 \mathrm{~km}^{2}$ (Breitenmoser-Würsten et al., 2001). Areas with lynx adjacent to the north-west Swiss Alps are Valais to the south, and the west central Swiss Alps to the east.

The Jura Mountains are a secondary limestone mountain chain forming the north-west border of Switzerland with France (for details see Breitenmoser et al., 1993a; Fig. 1). They are less fragmented than the Alps, forming a block of contiguous suitable habitat of $6,670 \mathrm{~km}^{2}$ (Zimmermann \& Breitenmoser, in press). In contrast to the north-west Swiss Alps, prey base was not a limiting factor during the study period. The number of roe deer killed per $1 \mathrm{~km}^{2}$ of forest increased continuously since 1990 in the southern part of the Jura Mountains (Fig. 2), as well as in France (Stahl et al., 2001). The overall lynx density in the main study area remained fairly constant over the whole study period and was estimated at $0.7-0.8$ residents per $100 \mathrm{~km}^{2}$ (Breitenmoser-Würsten et al., in press).

The study area in each region was defined as the area formed by the $1 \mathrm{~km}$ buffered 100\% minimum convex polygon (MCP) of all adult resident females from which juveniles were caught and observed during dispersal (Fig. 1).

\section{Field study}

From 1988 to 2001 dispersal characteristics (Table 1) were obtained for 22 and 17 lynx in the north-west Swiss Alps and Jura Mountains, respectively. Dispersal data came mainly from radio-telemetry; additional information was available from kittens tagged at the den and later live-trapped or photographed by a camera trap. Details of capture, handling, radio-telemetry and number of locations are in Zimmermann et al. (2005). Only radio fixes with an accuracy of $1 \mathrm{~km}^{2}$ or better were considered. We located dispersing lynx almost every day when they moved through new terrain, and at least every week once home ranges were established for $>1$ month. After independence subadults were considered dispersers when they established a home range that overlapped by $\leq 5 \%$ of their natal (maternal) home range (based on a $90 \% \mathrm{MCP}$ ) or were last located outside their natal area for those that either died or lost contact before forming a home range (Sweanor et al., 2000). Percentage overlap of total ranges and home ranges between animals A and B was calculated as 


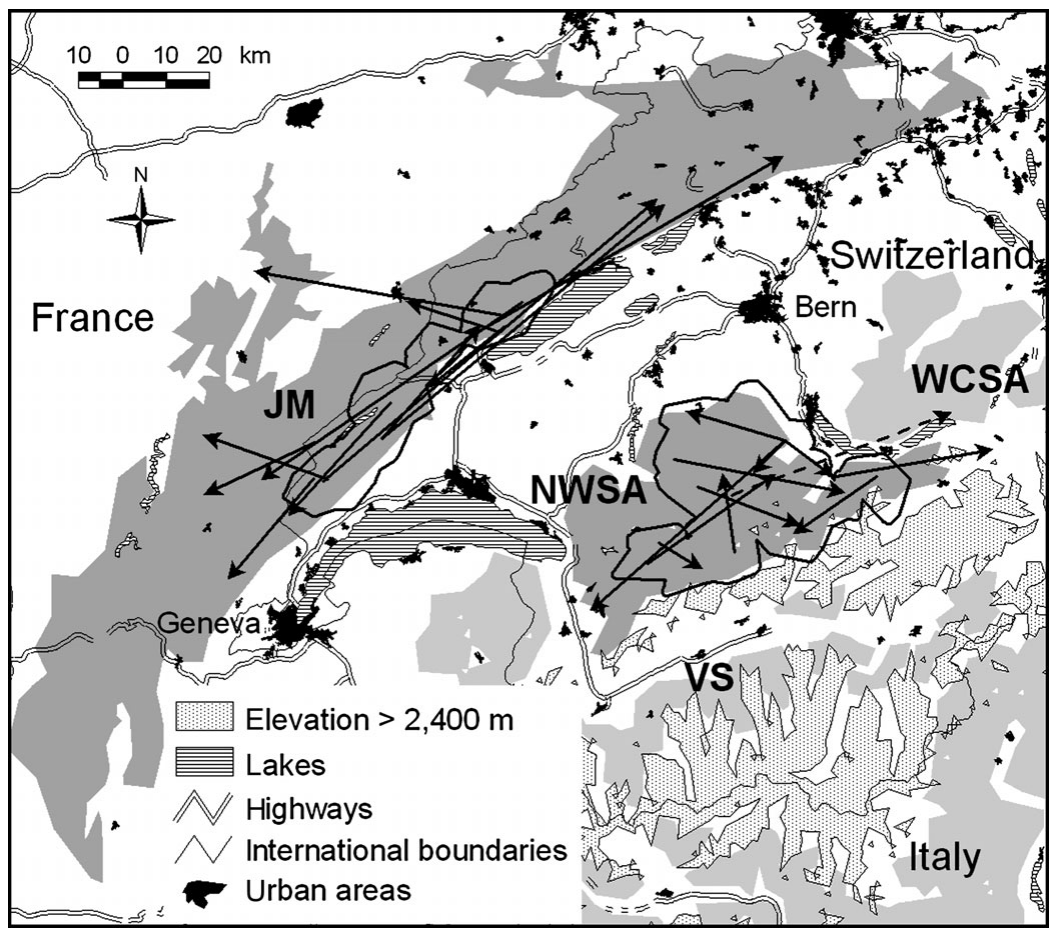

Fig. 1 Location of the study sites in Switzerland. Suitable lynx habitat patches in the north-west Swiss Alps (NWSA) and the Jura Mountains (JM) are dark grey; the adjoining patches of Valais (VS) and west central Swiss Alps (WCSA) are light grey. Thick black lines show the main study areas (see text for further details). Arrows indicate dispersal directions, distances and endpoints for 12 lynx in NWSA and 12 lynx in JM. Movements are shown as straight lines from a lynx's natal home range centre or its capture site to its independent home range centre, mortality site or last location. All subadults settled in their natal habitat patch, except one male that left NWSA (dashed line).

$$
\sqrt{(\text { overlap } A B / \text { range } A) *(\text { overlap } A B / \text { range } B)}
$$

All other independent progeny (those establishing home ranges with $>5 \%$ overlap with their natal range) were considered philopatric $(\mathrm{Ph})$. Dispersal began when a subadult made its first move outside its natal home range without returning. Dispersers were classified as: (1) dispersers (Di) that most likely completed their natal dispersal and exhibited 6 months of site fidelity suggestive of home range establishment and/or reached sexual maturity, or (2) failed dispersers (fD) that exhibited $<6$ months site fidelity and/or died before they established a home range. Lynx normally reach sexual maturity at 2.75 years for males and 1.75 years for females. In one study (Kvam, 1991) some males and almost 50\% of females reached sexual maturity one year earlier but we never observed such early maturity. A limit of 6 months was chosen for site fidelity because all dispersers, with the exception of one male that stayed for 200 days, left their transient home range after 72 114 days (median 113 days, $\mathrm{n}=5$; Zimmermann et al., 2005).

\section{Data analysis}

The dispersal direction was defined as the vector from the centre (arithmetic mean of $\mathrm{x}$ and $\mathrm{y}$ coordinates of all radio fixes) of the natal home range to the centre of the independent home range. Directional data were transformed to unimodal data and subjected to Rayleigh's test (Zar, 1984) to examine whether dispersal directions were distributed uniformly or not. Centroid distance (CD; Fig. 3) was the distance from the centre of a progeny's natal home range to the centre of its independent home range. When complete dispersal information was not available, dispersal distances and directions were calculated based on one of the following combinations: centre of natal

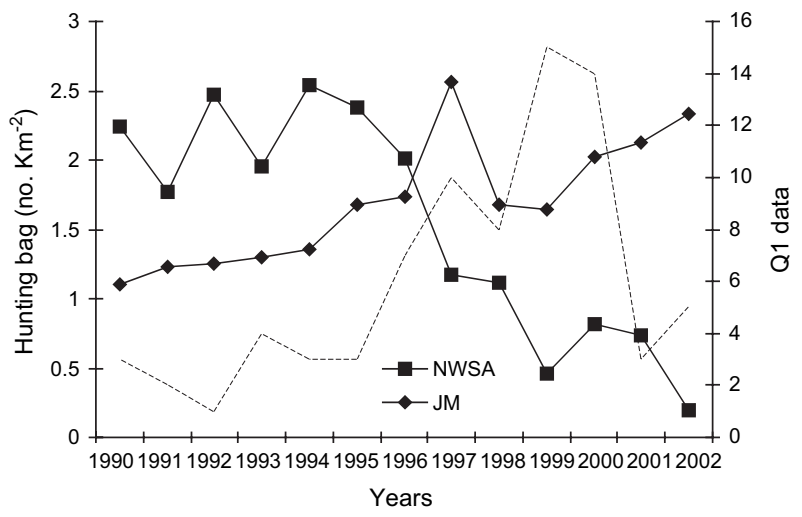

Fig. 2 Roe deer hunting bag (number killed per $\mathrm{km}^{2}$ forest) from 1990 to 2002 in the north-west Swiss Alps (NWSA) and the Jura Mountains (JM). The hunting quotas are fixed each year according to estimates of population size and trend. The broken line shows the evolution of the Q1 (see text for details) signs of lynx presence in the north-west Swiss Alps. 
Table 1 Characteristics and fate of juvenile lynx (M, male; F, female; FB, females ear-tagged as juveniles) followed in the north-west Swiss Alps and the Jura Mountains (Zimmermann et al., 2005), with the maternal lines, date of first observation, method used to track each individual, and the fate of each individual.

\begin{tabular}{|c|c|c|c|c|c|}
\hline Lynx & $\begin{array}{l}\text { Kitten } \\
\text { of female }\end{array}$ & $\begin{array}{l}\text { Date of first } \\
\text { observation }\end{array}$ & Method $^{1}$ & $\begin{array}{l}\text { Date of last } \\
\text { observation }\end{array}$ & Fate $^{2}$ \\
\hline \multicolumn{6}{|c|}{ North-west Swiss Alps } \\
\hline M18 & F37 & 22/01/1997 & $\mathrm{rt}, \mathrm{ct}$ & $16 / 05 / 1999$ & Alive, [reproduced] \\
\hline M20 & F30 & 25/03/1997 & $\mathrm{rt}$, ct & 02/12/1998 & Alive \\
\hline M24 & F47 & $24 / 02 / 1998$ & $\mathrm{rt}, \mathrm{ct}$ & $27 / 01 / 2004$ & Alive, reproduced \\
\hline M25 & F33 & 28/06/1997 & den, $\mathrm{rt}$ & $14 / 09 / 2000$ & Alive, [reproduced] \\
\hline M28 & & 30/01/1999 & rt & $12 / 02 / 1999$ & Died, starvation \\
\hline M29 & F34 & $25 / 06 / 1998$ & den, rt, ct & $07 / 05 / 2003$ & Alive, [reproduced] \\
\hline M30 & & 05/03/1999 & rt & 21/09/1999 & Died, disease \\
\hline M31 & F52 & 08/12/1998 & $\mathrm{ct}, \mathrm{rt}$ & $10 / 08 / 2000$ & Alive \\
\hline M35 & F35 & $31 / 10 / 1998$ & $\mathrm{ct}, \mathrm{rt}, \mathrm{ct}$ & $12 / 02 / 2004$ & Alive, [reproduced] \\
\hline F31 & F32 & 06/01/1997 & $\mathrm{rt}, \mathrm{ct}$ & $26 / 09 / 1998$ & Alive, [reproduced] \\
\hline $\mathrm{F} 33^{3}$ & & $14 / 01 / 1997$ & $\mathrm{rt}$ & $23 / 07 / 1998$ & Alive, reproduced \\
\hline $\mathrm{F} 40$ & & $13 / 03 / 1997$ & rt & $20 / 03 / 1998$ & Unknown \\
\hline $\mathrm{F} 42^{3}$ & & 05/04/1997 & $\mathrm{rt}, \mathrm{ct}$ & $11 / 01 / 2004$ & Alive, reproduced \\
\hline $\mathrm{F} 46^{3}$ & & $15 / 11 / 1997$ & $\mathrm{rt}$ & $20 / 01 / 1998$ & Died, car accident \\
\hline F48 & F38 & 05/07/1997 & den, $\mathrm{rt}$ & $18 / 05 / 1998$ & Unknown \\
\hline F49 & F34 & 23/06/1997 & den, $r t$ & $27 / 08 / 1999$ & Alive, [reproduced] \\
\hline F50 & F37 & $13 / 03 / 1998$ & rt & $19 / 05 / 1998$ & Unknown \\
\hline $\mathrm{F} 54^{3}$ & & $14 / 08 / 1999$ & $\mathrm{rt}$ & $23 / 06 / 2000$ & Alive, [reproduced] \\
\hline F56 & F32 & $08 / 02 / 2000$ & $\mathrm{rt}$ & $25 / 02 / 2000$ & Unknown \\
\hline $\mathrm{F} 57^{3}$ & & $08 / 05 / 2000$ & $\mathrm{rt}$ & $10 / 03 / 2001$ & Alive \\
\hline FB22 & F34 & $25 / 06 / 1998$ & den, ct, cr & $18 / 10 / 2001$ & Alive, [reproduced] \\
\hline FB44 & F34 & $11 / 12 / 2001$ & ct & $01 / 08 / 2003$ & Alive, [reproduced] \\
\hline \multicolumn{6}{|c|}{ Jura Mountains } \\
\hline M11 & $\mathrm{F} 21$ & $19 / 06 / 1993$ & den, $r t, c r$ & $08 / 02 / 2002$ & Alive, reproduced \\
\hline M13 & F18 & $18 / 06 / 1993$ & den, rt & $27 / 06 / 1995$ & Alive, [reproduced] \\
\hline M14 & $\mathrm{F} 21$ & $31 / 12 / 1995$ & $\mathrm{rt}$ & $26 / 02 / 1998$ & Alive, [reproduced] \\
\hline M15 & F18 & 23/06/1995 & den, $\mathrm{rt}$ & $21 / 09 / 1996$ & Died, illegal killing \\
\hline M16 & F11 & $08 / 03 / 1990$ & $\mathrm{rt}$ & $19 / 06 / 1990$ & Died, disease \\
\hline F12 & F11 & $20 / 04 / 1988$ & $\mathrm{rt}$ & $20 / 12 / 1988$ & Died, illegal killing \\
\hline F13 & F11 & $23 / 03 / 1989$ & $\mathrm{rt}$ & $17 / 08 / 1989$ & Died, disease \\
\hline F17 & F14 & $25 / 03 / 1990$ & $\mathrm{rt}$ & $23 / 05 / 1990$ & Died, car accident \\
\hline F19 & F18 & 04/03/1991 & $\mathrm{rt}$ & 05/05/1991 & Unknown \\
\hline F20 & F11 & $16 / 03 / 1991$ & $\mathrm{rt}$ & ??/11/1995 & Alive, reproduced \\
\hline F22 & F18 & 04/03/1992 & $\mathrm{rt}$ & $25 / 11 / 1994$ & Alive, reproduced \\
\hline $\mathrm{F} 23$ & F15 & $14 / 03 / 1992$ & $\mathrm{rt}$ & $15 / 02 / 1995$ & Alive, reproduced \\
\hline F25 & F30 & $20 / 12 / 1995$ & $\mathrm{rt}$ & $02 / 07 / 1996$ & Unknown \\
\hline F26 & F18 & $23 / 06 / 1995$ & den, rt, ct & $08 / 01 / 2003$ & Alive, reproduced \\
\hline F27 & F24 & $30 / 06 / 1995$ & den, rt & $27 / 04 / 1996$ & Unknown \\
\hline $\mathrm{F} 28$ & F24 & $27 / 06 / 1995$ & den, $\mathrm{rt}$ & 04/03/1996 & Unknown \\
\hline F36 & F29 & 04/03/1997 & $\mathrm{rt}$ & $24 / 06 / 1998$ & Alive, [reproduced] \\
\hline
\end{tabular}

${ }^{1}$ Den, individual ear-tagged as kitten; rt, radio-telemetry; ct, camera-trap; cr, carcass retrieved

${ }^{2}$ Alive, survived the full year after separation from mother; reproduced, strong evidence from genetic analyses or field observations that individuals have reproduced; [reproduced], lynx reached sexual maturity (according to definition of Kvam, 1991) but there was no proof of reproduction

${ }^{3}$ First observed as subadults after separation from mother

home range to mortality site or last location, or capture site to centre of independent home range, mortality site or last location. The dispersal distance was also expressed relatively as the number of sex-specific home ranges crossed during dispersal. The size of male and female home ranges, respectively, was calculated as the diameter (d) of a circle with an area equal to the average home range size (HR) for adult male and female lynx in the study areas (north-west Swiss Alps: BreitenmoserWürsten et al., 2001; Jura Mountains: BreitenmoserWürsten et al., in press):

$$
d=2 \sqrt{H R / \pi}
$$

The total dispersal distance (TD, Fig. 3) was the sum of distances between consecutive locations (only one radio-telemetry fix per day considered) of subadults 


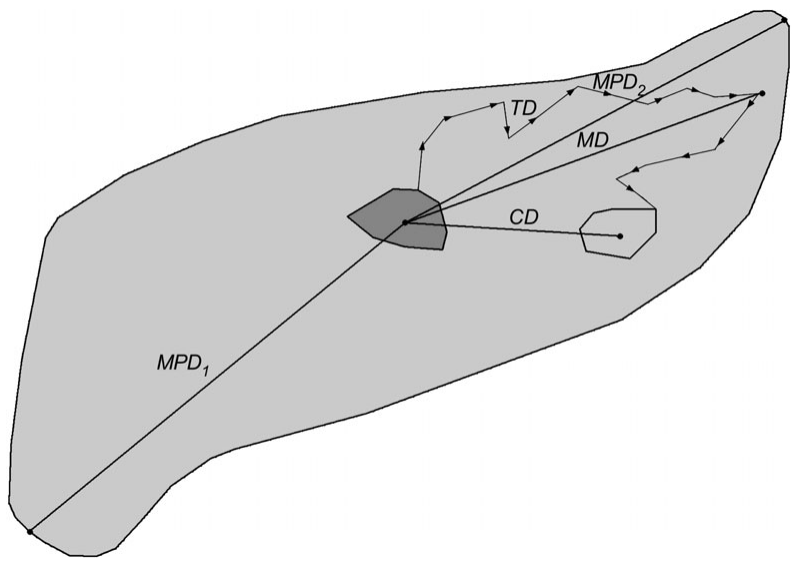

Fig. 3 Definitions of the measured dispersal distances of subadult lynx. Centroid distance (CD) is distance from arithmetic centre of natal home range (solid grey minimum convex polygon, $\mathrm{MCP}$ ) to arithmetic centre of independent home range (light grey MCP). Total distance (TD) is sum of distances between consecutive locations during dispersal (measured from the point the subadult left the natal home range to the point when it entered its independent home range); maximum distance (MD) is longest distance a dispersing lynx was ever located from the centroid of its natal range; maximum possible distance $1\left(\mathrm{MPD}_{1}\right)$ is distance from the centroid of the natal range to the farthest edge of good lynx habitat (light grey area); maximum possible distance $2\left(\mathrm{MPD}_{2}\right)$ is distance from the centre of the natal home range to the most distant good lynx habitat edge in the initial dispersal direction.

during their dispersal. The measures were taken from the point the subadult left the natal home range to the point when entering its subsequent home range. When subadults established more than one home range, the total distances between the ranges were summed. The maximum dispersal distance (MD; Fig. 3) was the largest distance a dispersing lynx was ever located from the centre of its natal home range. We compared MD with two maximum possible dispersal distances: from the centre of the natal range to the farthest edge of good lynx habitat that could be accessed within the same area $\left(\mathrm{MPD}_{1}\right.$; Fig. 3) and to the most distant good lynx habitat edge in the initial dispersal direction chosen by the respective subadult $\left(\mathrm{MPD}_{2}\right.$; Fig. 3). The areas of good lynx habitat were derived from lynx habitat models developed for the Alps (Zimmermann, 2004) and the Jura Mountains (Zimmermann \& Breitenmoser, in press). We used the Mann-Whitney U-test (Zar, 1984) to compare dispersal distances between sexes and study areas, and the Wilcoxon paired-sample test (Zar, 1984) to compare MD with $\mathrm{MPD}_{1}, \mathrm{MPD}_{2}$ and $\mathrm{CD}$. Comparisons were made between (i) all subadults (Ph, fD and Di), (ii) only individuals that dispersed (fD, Di) and (iii) only those that completed dispersal (Di). Centroid distance of $\mathrm{Ph}, \mathrm{fD}$ and $\mathrm{Di}$ is equivalent to the recovery distance, with the centroid distance of Di describing the effective dispersal (Trewhella et al., 1988).

To assess the effect of increased lynx abundance in, and dispersal from, the north-west Swiss Alps on lynx presence in neighbouring areas, we used information from a standardized monitoring system (see Capt et al., 1998, for details). All data were calibrated according to the criteria defined for the pan-Alpine monitoring (Molinari-Jobin et al., 2001), which defines three levels of reliability (Q1, Q2 and Q3). We considered only confirmed data (Q1 and Q2) to compare lynx presence and population trends in neighbouring areas but excluded depredation reports, as livestock is not consistently available in all areas.

\section{Results}

Only two females out of 14 subadults in the Jura Mountains and one male out of 13 subadults in the north-west Swiss Alps (F23, F36 and M30; Table 2) remained philopatric, and M30 died after a short dispersal (Fig. 3). Seven out of 9 subadults from the Jura Mountains that completed dispersal left the main study area whereas three out of $12 \mathrm{did}$ so in the north-west Swiss Alps. None of the subadults left the Jura Mountains whereas one (M18) left the north-west Swiss Alps.

In both areas no difference between sexes was observed for centroid, total or maximum dispersal distances whichever dispersal category was considered (all $P>0.05)$. Males and females were therefore pooled for all subsequent analyses. Centroid distances were $4.5-56.0 \mathrm{~km}$ in the north-west Swiss Alps and 2.1$97.3 \mathrm{~km}$ in the Jura Mountains (Table 2). Subadult lynx that completed and/or had a fatal dispersal dispersed further in the Jura Mountains than in the north-west Swiss Alps: centroid distance was higher in the Jura Mountains than in the north-west Swiss Alps when either both fatal (fD) and completed dispersal (Di) or when only completed dispersal (Di) was considered but did not differ when all individuals $(\mathrm{Ph}+\mathrm{fD}+\mathrm{Di})$ were included (Table 3).

Median recovery distance $(\mathrm{CD}$ of $\mathrm{Ph}, \mathrm{fD}$ and $\mathrm{Di})$ in the north-west Swiss Alps was 2.0 (range 0.4-5.6) times the mean circular resident female's home range diameter and 1.4 (range 0.3-3.8) times the mean circular resident male's home range diameter. In the Jura Mountains, it was 2.0 (range 0.1-6.6) and 1.5 (range 0.1-5.1) times the respective means. Median effective dispersal distance (CD of $\mathrm{Di}$ ) was 2.1 (range 0.4-5.6) times female home range diameter and 1.5 (range $0.3-3.8$ ) times the mean resident male's home range diameter in the north-west Swiss Alps. In the Jura Mountains it was 4.7 (range 0.16.6) and 3.6 (range 0.1-5.1) times the respective means. 
Table 2 Dispersal type of 13 subadult lynx in the north-west Swiss Alps and 14 in the Jura Mountains with centroid, total, maximum dispersal distances, and maximum possible distances $\left(\mathrm{MPD}_{1}\right.$ and $\left.\mathrm{MPD}_{2}\right)$, and \% overlap with maternal home range. Centroid distance is also expressed as number of mean circular resident female and male home range diameters, respectively. See text and Fig. 3 for further details of the dispersal distances.

\begin{tabular}{|c|c|c|c|c|c|c|c|c|c|}
\hline \multirow[b]{2}{*}{ Lynx } & \multirow[b]{2}{*}{ Dispersal type $^{1}$} & \multicolumn{3}{|c|}{ Centroid distance } & \multirow{2}{*}{$\begin{array}{l}\text { Total } \\
\text { distance } \\
(\mathrm{km})\end{array}$} & \multirow[b]{2}{*}{$\begin{array}{l}\text { Maximum } \\
\text { distance }(\mathrm{km})\end{array}$} & \multirow[b]{2}{*}{$\begin{array}{l}\mathrm{MPD}_{1} \\
(\mathrm{~km})\end{array}$} & \multirow[b]{2}{*}{$\begin{array}{l}\mathrm{MPD}_{2} \\
(\mathrm{~km})\end{array}$} & \multirow{2}{*}{$\begin{array}{l}\text { Overlap with } \\
\text { maternal } \\
\text { home range }(\%)\end{array}$} \\
\hline & & $\mathrm{km}$ & $\begin{array}{l}\text { No. } \text { + HR } \\
\text { diameter }\end{array}$ & $\begin{array}{l}\text { No. } \widehat{\jmath} \mathrm{HR} \\
\text { diameter }\end{array}$ & & & & & \\
\hline \multicolumn{10}{|c|}{ North-west Swiss Alps } \\
\hline M18 & $\mathrm{Di}$ & 50.7 & 5 & 3.5 & & & 50 & 50 & 0 \\
\hline M20 & $\mathrm{Di}$ & 15.2 & 1.5 & 1 & & & 53 & 53 & 0 \\
\hline M24 & $\mathrm{Di}$ & 4.5 & 0.4 & 0.3 & 157 & 43.2 & 68 & 68 & 0.8 \\
\hline M25 & $\mathrm{Di}$ & 33.1 & 3.3 & 2.3 & 36 & 28.8 & 73 & 73 & 0 \\
\hline M29 & $\mathrm{Di}$ & 56 & 5.6 & 3.8 & 81 & 68.2 & 65 & 65 & 0 \\
\hline М30 & $\mathrm{fD}$ & 5.1 & 0.5 & 0.3 & 62 & 17.2 & 65 & 4 & $+^{2}$ \\
\hline M31 & $\mathrm{Di}$ & 36.7 & 3.6 & 2.5 & 164 & 51.2 & 63 & 63 & 0 \\
\hline M35 & $\mathrm{Di}$ & 20.1 & 2 & 1.4 & & & 76 & & 0 \\
\hline F31 & $\mathrm{Di}$ & 22.1 & 2.2 & 1.5 & 55 & 22 & 58 & 58 & 0 \\
\hline F40 & $\mathrm{Di}$ & 33.3 & 3.3 & 2.3 & 69 & 35.9 & 68 & 25 & 0 \\
\hline F49 & $\mathrm{Di}$ & 7.4 & 0.7 & 0.5 & 2 & 17.4 & 65 & 65 & 0 \\
\hline FB22 & $\mathrm{Di}$ & 10.7 & 1.1 & 0.7 & & & 65 & & 0 \\
\hline FB44 & $\mathrm{Di}$ & 20.6 & 2 & 1.4 & & & 65 & & 0 \\
\hline Median & & 20.6 & 2 & 1.4 & 65.5 & 32.4 & 65 & 60.5 & \\
\hline \multicolumn{10}{|c|}{ Jura Mountains } \\
\hline M11 & Di & 31.4 & 2.1 & 1.6 & & & 156 & & 0 \\
\hline M13 & $\mathrm{Di}$ & 97.3 & 6.6 & 5.1 & & & 173 & & 0 \\
\hline M14 & $\mathrm{Di}$ & 81.1 & 5.5 & 4.3 & 86 & 75.7 & 156 & 156 & 0 \\
\hline M15 & $\mathrm{fD}$ & 27 & 1.8 & 1.4 & 14 & 21 & 175 & 104 & 0 \\
\hline M16 & $\mathrm{fD}$ & 19.1 & 1.3 & 1 & 52 & 28 & 157 & 157 & 0 \\
\hline F12 & $\mathrm{Di}$ & 80.7 & 5.5 & 4.2 & 70 & 68.9 & 150 & 128 & 0 \\
\hline F13 & $\mathrm{fD}$ & 18.4 & 1.3 & 1 & 19 & 18.4 & 155 & 155 & 0 \\
\hline F17 & $\mathrm{fD}$ & 31.9 & 2.2 & 1.7 & 68 & 51 & 151 & 127 & 0 \\
\hline F20 & Di & 54.9 & 3.7 & 2.9 & 99 & 45.7 & 159 & 159 & 0 \\
\hline F22 & $\mathrm{Di}$ & 27.6 & 1.9 & 1.4 & 72 & 35.5 & 172 & 105 & 0 \\
\hline F23 & $\mathrm{Ph}$ & 11 & 0.7 & 0.6 & 51 & 34 & 143 & 143 & 12.2 \\
\hline F25 & $\mathrm{fD}$ & 24.9 & 1.7 & 1.3 & 91 & 46.8 & 170 & 112 & 0 \\
\hline F26 & $\mathrm{Ph}$ & 2.1 & 0.1 & 0.1 & 52 & 30 & 176 & 176 & 47.2 \\
\hline F36 & $\mathrm{Di}$ & 68.8 & 4.7 & 3.6 & 110 & 53.3 & 164 & 164 & 0 \\
\hline Median & & 29.5 & 2 & 1.5 & 69 & 40.6 & 158 & 149 & \\
\hline
\end{tabular}

${ }^{1} \mathrm{Ph}$, remained philopatric; $\mathrm{Di}$, individuals that most likely completed their dispersal (6 months of site fidelity suggestive of home range establishment and/or surveyed until sexual maturity); $\mathrm{fD}$, failed dispersal ( $<6$ months site fidelity and/or died before establishing a home range)

${ }^{2}$ Overlap, but maternal home range not known exactly

Dispersal directions of individuals that either failed or completed dispersal (Table 2) were randomly distributed in the north-west Swiss Alps, but not in the Jura Mountains (Rayleigh test; north-west Swiss Alps: $\mathrm{Z}=2.1, \mathrm{n}=12, \mathrm{P}>0.1$; Jura Mountains: $\mathrm{Z}=5.5, \mathrm{n}=$ $12,0.002<\mathrm{P}<0.005)$. The main dispersal direction in the Jura Mountains was to the south-west and north-east, corresponding approximately to the orientation of the predominant ridgelines of this mountain range (Fig. 1). The total and maximum dispersal distances were 2.0$164.0 \mathrm{~km}$ and $17.2-68.2 \mathrm{~km}$, respectively, in the north-west Swiss Alps and 14.0-110.0 km and 21.0-75.7 km, respectively, in the Jura Mountains (Table 2). Total and maximum dispersal distances did not differ significantly between the two areas whichever dispersal category was considered (Table 3).

In the north-west Swiss Alps CD was smaller than $\mathrm{MD}$, indicating a circular dispersal, when all individuals, and only individuals that exhibited fatal or completed dispersal, were compared (Table 4), but did not differ for individuals that completed dispersal. No difference between $\mathrm{CD}$ and $\mathrm{MD}$ was observed in the Jura Mountains (Table 4).

In both areas the maximum distance was smaller than $\mathrm{MPD}_{1}$ whichever dispersal category was considered but was significantly smaller than $\mathrm{MPD}_{2}$ for all comparisons in the Jura Mountains but did not differ in the northwest Swiss Alps, indicating that in the latter most of the 
Table 3 Statistical comparison between the centroid, total and maximum dispersal distances (medians with sample size in parentheses) of subadult lynx in the north-west Swiss Alps (NWSA) and the Jura Mountains (JM), using the Mann-Whitney $U$ statistic. See text and Fig. 3 for further details of the three distances.

\begin{tabular}{|c|c|c|c|c|c|c|c|c|c|c|c|c|}
\hline \multirow[b]{2}{*}{ Dispersal type* } & \multicolumn{4}{|c|}{ Centroid distance $(\mathrm{km})$} & \multicolumn{4}{|c|}{ Total distance $(\mathrm{km})$} & \multicolumn{4}{|c|}{ Maximum distance $(\mathrm{km})$} \\
\hline & NWSA & $\mathrm{JM}$ & $U$ & $\mathrm{P}$ & NWSA & JM & $U$ & $\mathrm{P}$ & NWSA & $\mathrm{JM}$ & $U$ & $\mathrm{P}$ \\
\hline $\mathrm{Ph}+\mathrm{fD}+\mathrm{Di}$ & $20.6(13)$ & $29.5(14)$ & 64 & 0.19 & $65.5(8)$ & $69(12)$ & 46 & 0.88 & $32.4(8)$ & $40.6(12)$ & 36 & 0.35 \\
\hline $\mathrm{fD}+\mathrm{Di}$ & $20.6(13)$ & 31.7 (12) & 42 & 0.05 & $65.5(8)$ & $71(10)$ & 38 & 0.86 & $32.4(8)$ & $46.3(10)$ & 28 & 0.28 \\
\hline $\mathrm{Di}$ & $21.4(12)$ & $68.8(7)$ & 11 & 0.01 & $69(7)$ & $86(5)$ & 12 & 0.37 & $35.9(7)$ & $53.3(5)$ & 7 & 0.09 \\
\hline
\end{tabular}

*See footnote to Table 2

subadults reached the edge of suitable habitat during their dispersal (Table 4). The suitable habitat patch in the Jura Mountains is larger than in the north-west Swiss Alps as $\mathrm{MPD}_{1}$ and $\mathrm{MPD}_{2}$ were significantly higher in the former (all $\mathrm{P}<0.05$ ).

In the north-west Swiss Alps four out of nine subadults, all males, went beyond the edge of good lynx habitat while dispersing. Only M18, however, reached the neighbouring area of the west central Swiss Alps (Fig. 1). The three other males (M24, M29 and M30) returned after having spent a few days in the vicinity of a highway. Two of them (M24 and M30) turned back close to the place where they initially started their dispersal. M30 in the north-west Swiss Alps (Fig. 4) and M16 in the Jura Mountains, covered a considerable distance through sparsely wooded areas of the Swiss Plateau before returning to their respective mountain ranges.

The monitoring data showed a significant increase in lynx abundance in the north-west Swiss Alps from the

Table 4 Statistical comparison between the centroid distance (CD) and maximum distance (MD) and between the maximum distance (MD) and maximum possible distances $\left(\mathrm{MPD}_{1}\right.$ and $\left.\mathrm{MPD}_{2}\right)$ of dispersing subadult lynx in the north-west Swiss Alps and the Jura Mountains using a Wilcoxon paired-sample test (Z). See text and Fig. 3 for further details of $C D, M D, M P D_{1}$ and $\mathrm{MPD}_{2}$.

\begin{tabular}{|c|c|c|c|c|c|c|}
\hline \multirow[b]{2}{*}{ Comparison* } & \multicolumn{3}{|c|}{ NW Swiss Alps } & \multicolumn{3}{|c|}{ Jura Mountains } \\
\hline & $\mathrm{n}$ & $Z$ & $\mathrm{P}$ & $\mathrm{n}$ & $Z$ & $\mathrm{P}$ \\
\hline \multicolumn{7}{|l|}{ CD/MD } \\
\hline $\mathrm{Ph}+\mathrm{fD}+\mathrm{Di}$ & 8 & 1.96 & $<0.05$ & 12 & 1.07 & 0.29 \\
\hline $\mathrm{fD}+\mathrm{Di}$ & 8 & 1.96 & $<0.05$ & 10 & 0.18 & 0.86 \\
\hline $\mathrm{Di}$ & 7 & 1.69 & 0.09 & 5 & 1.48 & 0.13 \\
\hline \multicolumn{7}{|l|}{ MD/MPD 1} \\
\hline $\mathrm{Ph}+\mathrm{fD}+\mathrm{Di}$ & 8 & 2.38 & 0.02 & 12 & 3.06 & $<0.01$ \\
\hline $\mathrm{fD}+\mathrm{Di}$ & 8 & 3.06 & $<0.01$ & 10 & 2.80 & $<0.01$ \\
\hline Di & 7 & 2.20 & 0.03 & 5 & 2.02 & 0.04 \\
\hline \multicolumn{7}{|l|}{$\mathrm{MD} / \mathrm{MPD}_{2}$} \\
\hline $\mathrm{Ph}+\mathrm{fD}+\mathrm{Di}$ & 8 & 1.54 & 0.12 & 12 & 3.06 & $<0.01$ \\
\hline $\mathrm{fD}+\mathrm{Di}$ & 8 & 1.54 & 0.12 & 10 & 2.80 & $<0.01$ \\
\hline Di & 7 & 1.86 & 0.06 & 5 & 2.02 & 0.04 \\
\hline
\end{tabular}

*See footnote to Table 2 middle to the end of the 1990s followed by a decrease (Fig. 5b). No significant increase in lynx abundance could, however, be observed in the neighbouring areas of Valais and the west central Swiss Alps, even after a time lag of 3 years (Fig. 5a,c).

\section{Discussion}

Subadults from the north-west Swiss Alps and the Jura Mountains appeared to have the same dispersal potential as there were no observed differences between the two areas in the total and maximum distances dispersed. Contrary to our expectation, centroid dispersal distances did not differ between the two areas when all individuals were considered, and were only significantly smaller in the north-west Swiss Alps than in the Jura Mountains when individuals that most likely completed dispersal were considered. However, a larger proportion of individuals in the north-west Swiss Alps, all males, moved through unfavourable habitat but all stopped at fenced highways and turned back, except M18 which left the area. Two of the individuals settled in, or in the vicinity of, their maternal home range. Subadult lynx appear, therefore, to have a low capability to move through unfavourable habitat and to cross linear barriers such as fenced highways. Observations from adult radio-tagged lynx, which sometimes roam far outside their home ranges show, however, that lynx can cross such obstacles (Breitenmoser-Würsten et al., 2001; Ryser et al., 2004).

The apparent reduced ability of subadults to cross barriers led to circular dispersal in the case of two males in the north-west Swiss Alps. Similarly, severe habitat restriction led to philopatry in male cougar Puma concolor coryi in Florida, where they returned to the vicinity of their natal areas after unfruitful dispersal attempts (Maehr et al., 2002). A similar process was described for the Iberian lynx Lynx pardinus (Ferreras et al., 2004). Habitat quality and barriers also shaped dispersal directions. In the north-west Swiss Alps, with no parallel ridgelines, dispersal directions were oriented randomly 


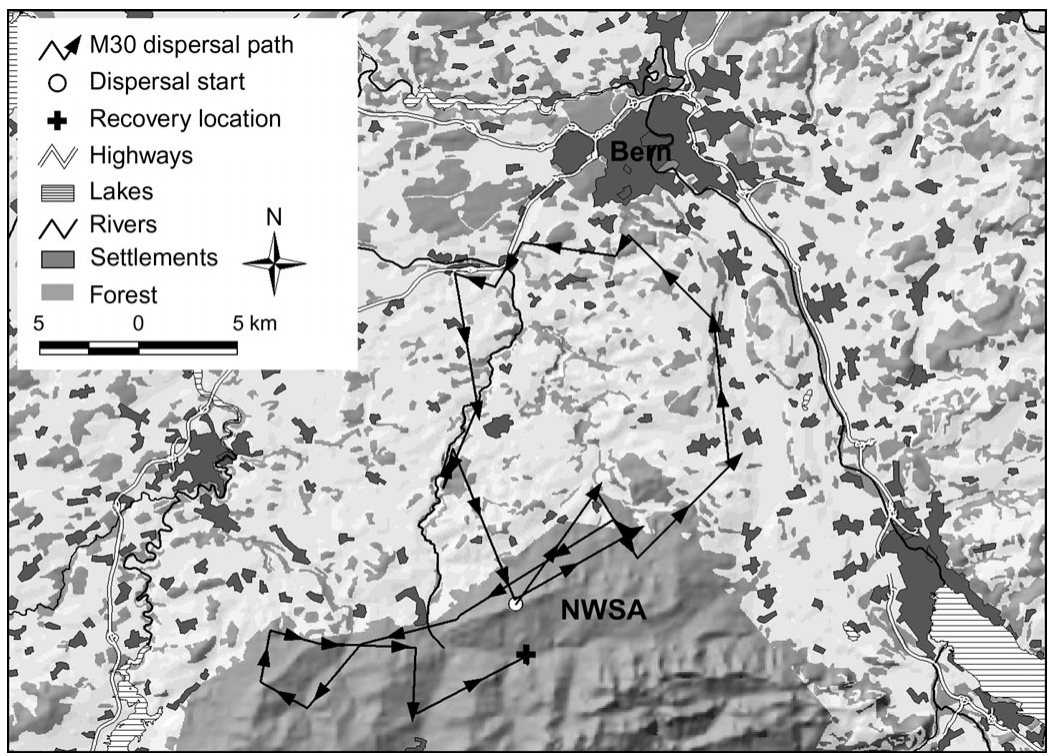

Fig. 4 Dispersal route of lynx M30. He traversed a sparsely wooded part of the Swiss Plateau and moved north until he reached the surroundings of Bern where he turned west. After moving into an area $8 \mathrm{~km}$ west of Bern he followed a fenced highway for $>4.5 \mathrm{~km}$ and spent a week in the vicinity of both the highway and a railway. He returned to the north-west Swiss Alps (NWSA) by moving along a river course. but the ridges of the Jura Mountains run south-west to north-east and this appeared to shape the movements of dispersing subadult lynx. The lack of south-east dispersal in the Jura Mountains may indicate hesitance to leave the continuous forest and travel over open agricultural areas. Similar behaviour has been reported in American black bears Ursus americanus in west Virginia that used the predominant ridgelines of the Appalachian Mountains as corridors (Lee \& Vaughan, 2003), and in red fox Vulpes vulpes in North Dakota where dispersal directions were altered by a 4-lane interstate highway (Allen \& Sargeant, 1993).

The most important outcome of our analysis, however, was that we failed to detect any positive densitydependent effects in lynx dispersal and hence cannot confirm the hypothesis that high population density will encourage the expansion of the population. Contrary to expectation a high proportion of subadults also dispersed in the Jura Mountains, an area with a lower lynx density and relatively high prey availability compared to the north-west Swiss Alps. Only one out of 12 individual lynx that completed dispersal actually left the north-west Swiss Alps, and the proportion of individuals leaving was smaller than in the Jura Mountains. As a consequence of the low rate of successful dispersals, the population pressure in the north-west Swiss Alps did not trigger an increase in lynx abundance in the two neighbouring areas (Fig. 5).

High lynx abundance can depress locally the numbers of roe deer and chamois Rupicapra rupicapra, lead to an increase in depredation on livestock, and ultimately diminish the acceptance of lynx by local people (Breitenmoser et al., 1999). In 2000 at least eight individuals were known to have been killed illegally
(Breitenmoser-Würsten et al., 2001) and four animals were removed as stock raiders during 1997-2001. In addition, six lynx were taken from the north-west Swiss Alps in 2001 for a translocation programme into the eastern Swiss Alps (Molinari-Jobin et al., 2001). All of these removals lead to a considerable reduction in abundance (Fig. 5).

Generally, there is good evidence in natural populations that dispersal rate increases with increasing competition for limited resources (Lambin et al., 2001) but dispersal rates have also been reported to be negatively density dependent, with a smaller fraction of individuals dispersing at higher densities (Wolff, 1997; Lambin et al., 2001). Furthermore, those that disperse may only move relatively short distances (McCarty, 1997). This pattern has been reported for Townsend's voles Microtus townsendii (Lambin, 1994), red foxes (Trewhella et al., 1988), and Canadian lynx (Breitenmoser et al., 1993b). The little data available (Schmidt et al., 1997; Sunde et al., 2000) indicate that median recovery distance may be negatively correlated with lynx density and positively with mean male and female home range diameter. With the exception of the hunted Norwegian population, lynx dispersed roughly 1.5 male or 2.0 female home range diameters when recovery distances were considered. If dispersal is negatively correlated with density, the longest dispersal distances should be observed in areas where the lynx density is low and the home ranges large. The data (Table 5) seem to confirm this. However, central and northern Europe (where densities are generally much lower) are not necessarily comparable.

In contrast to wolves and bears, which can disperse over long distances (Swenson et al., 1998; Merrill \& Mech, 2000; Stratman et al., 2001), subadult lynx are 

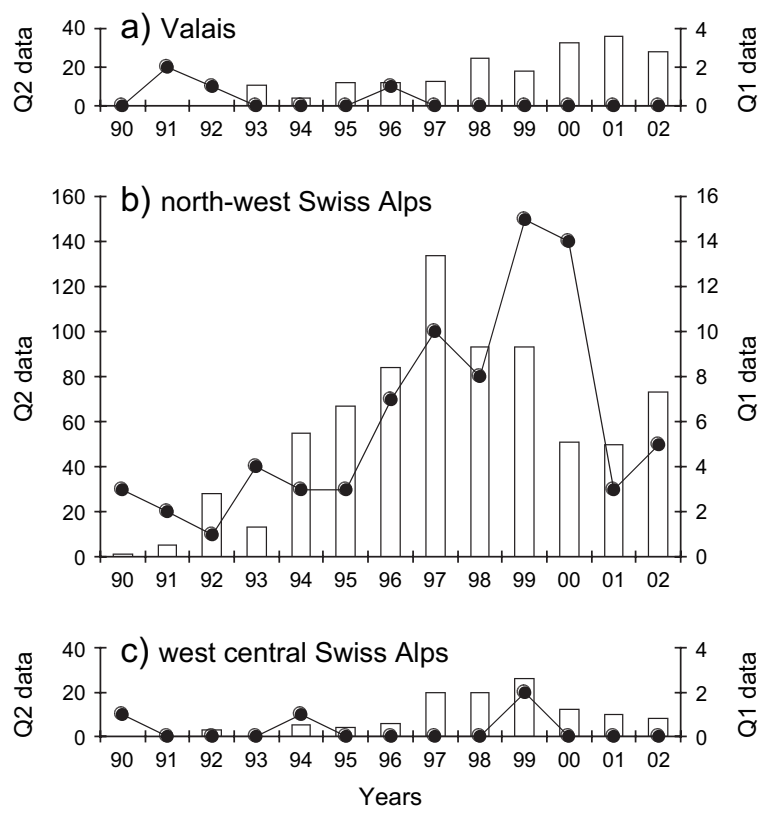

Fig. 5 Reported signs of lynx presence over 1990-2002 in (a) the Valais, (b) the north-west Swiss Alps and (c) the west central Swiss Alps. Reports of lynx killed or found dead, or young orphaned lynx caught and taken into captivity (Quality 1 , continuous line, right $\mathrm{y}$-axis), records of wild prey remains, tracks, scats, sightings, and vocalizations confirmed by trained personnel (Quality 2, columns, left y-axis).

conservative dispersers because of their life history and land tenure system and therefore maintain close contact to conspecifics (Zimmermann et al., 2005). Their low ability to cross major barriers such as fenced highways hampers the colonization of a fragmented landscape such as the Alps. In the long-term the population may yet disperse but because of prey depression and conflicts with local people high population densities are not maintained over long periods.

Natural spread of the species could potentially be increased by the use of wildlife crossings but the type of crossings that lynx will use have yet to be determined. Riparian vegetation may serve as natural corridors, as shown by the dispersal path of M30 (Fig. 4). Connectivity may be enhanced if wildlife crossings are established in the direction of predominant ridgelines or other landscape level features such as forests and riparian vegetation that may aid or direct dispersing lynx.

Our findings may have consequences for the design of carnivore reintroductions (Breitenmoser et al., 2001) or recovery programmes in fragmented landscapes. Rather than creating one population, population nuclei could be founded in several neighbouring patches through reintroductions or artificial transfer of individuals to neighbouring areas. Considering that dispersal may be inversely density dependent, such an approach may be a better release strategy for reintroduction, as dispersing animals may encounter conspecifics when moving away from the release site. In a reintroduction project in Austria lynx dispersed in all directions from the site of release (Gossow \& Honsig-Erlenburg, 1986) without founding a population.

To compensate for the lack of expansion of the Swiss populations six lynx from the north-west Swiss Alps and three from the Jura Mountains were translocated to the eastern part of Switzerland during the winters of $2000 / 2001$ and 2002/2003. This allowed reduction of locally high abundance in the north-west Swiss Alps and accelerated the desired spread of the species. Paradoxically, it is possible that the intervention in the north-west Swiss Alps and the resulting reduction of the population will now lead to an increased dispersal rate.

Table 5 Data on dispersal distances of Eurasian lynx in four European areas, sorted from low to high density, with mean resident male and female home range diameters (HR ø) and population densities (number of resident lynx $100 \mathrm{~km}^{-2}$ ), and median recovery distances and effective dispersal distances ( $\mathrm{km}$; see text for further details), with median number of mean circular resident female and male home range diameters crossed.

\begin{tabular}{|c|c|c|c|c|c|c|c|c|c|}
\hline \multirow[b]{3}{*}{ Location } & & & \multirow[b]{3}{*}{ Density } & \multicolumn{3}{|c|}{ Recovery distance } & \multicolumn{3}{|c|}{ Effective dispersal } \\
\hline & \multicolumn{2}{|c|}{ Mean HR $\varnothing(\mathrm{km})$} & & \multirow{2}{*}{$\begin{array}{l}\text { Median, } \\
\text { km (n) }\end{array}$} & \multicolumn{2}{|c|}{$\begin{array}{l}\text { Median no. of } \\
\text { HR ø crossed }\end{array}$} & \multirow{2}{*}{$\begin{array}{l}\text { Median, } \\
\text { km (n) }\end{array}$} & \multicolumn{2}{|c|}{$\begin{array}{l}\text { Median no. of } \\
\text { HR ø crossed }\end{array}$} \\
\hline & $\hat{0}$ & q & & & $\hat{o}$ & q & & $\hat{\jmath}$ & q \\
\hline Norway $^{1}$ & 48.4 & 26.2 & $0.3^{5}$ & $40.6(6)$ & 0.8 & 1.6 & $41.2(5)$ & 0.9 & 1.6 \\
\hline Jura Mountains $^{2}$ & 19.1 & 14.7 & 0.8 & $29.5(14)$ & 1.5 & 2.0 & $68.8(7)$ & 3.6 & 4.7 \\
\hline Poland ${ }^{3}$ & 16.9 & 13.0 & & $25.0(6)$ & 1.5 & 1.9 & $50.5(4)$ & 3.0 & 3.9 \\
\hline $\mathrm{Alps}^{4}$ & 14.6 & 10.1 & 1.5 & $20.6(13)$ & 1.4 & 2.0 & $21.4(12)$ & 1.5 & 2.1 \\
\hline
\end{tabular}

${ }^{1}$ Sunde et al. (2000)

${ }^{2}$ Breitenmoser-Würsten et al. (in press)

${ }^{3}$ Schmidt et al. (1997)

${ }^{4}$ Breitenmoser-Würsten et al. (2001)

${ }^{5}$ Managed population 
Even though there are more vacant territories for youngsters close to their birth place in controlled populations there is no evidence that dispersal is less common (Macdonald \& Johnson, 2001). If anything, control seems only to increase dispersal (Frank \& Woodroffe, 2001). Exchange between established neighbouring populations will almost certainly take place later on, as resident adult lynx, especially males, show a higher propensity to cross barriers than subadults, particularly during the mating season. This could help to improve genetic exchange between established subpopulations.

\section{Acknowledgements}

We thank C. Angst, A. Burri, S. Capt, J. Laass, P. Molinari, A. Molinari-Jobin, A. Ryser and many other colleagues for gathering data over the past 20 years, and P. Sunde who provided dispersal data for Norway. Hunting statistics were kindly provided by P. Demierre, P. Juesy, and S. Sachot. We also appreciated the assistance of J. Hausser with analysis and P. Jackson with English. We thank M. von Arx for valuable discussions, and P. Wandeler and D. Hetherington for providing helpful comments on a previous version of this manuscript. The study was funded by the FOEN, the Canton of Vaud, Bern and Fribourg, Pro Natura, WWF Switzerland, the Stotzer-Kästli Foundation, and the Dr. Berthold Suhner Foundation. Sources of the digital geographical database were the Federal Office of Topography and Swiss Federal Statistical Office GEOSTAT.

\section{References}

Allen, S.H. \& Sargeant, A.B. (1993) Dispersal patterns of red foxes relative to population density. Journal of Wildlife Management, 57, 526-533.

Boyd, D.K. \& Pletscher, D.H. (1999) Characteristics of dispersal in a colonizing wolf population in the central Rocky Mountains. Journal of Wildlife Management, 63, 1094-1108.

Breitenmoser, U. (1998) Large predators in the Alps: the fall and rise of man's competitors. Biological Conservation, 83, 279-289.

Breitenmoser, U., Breitenmoser-Würsten, Ch. \& Capt, S. (1998) Reintroduction and present status of the lynx in Switzerland. Hystrix, 10, 17-30.

Breitenmoser, U., Breitenmoser-Würsten, Ch., Capt, S., Ryser, A., Zimmermann, F., Angst, C., Olsson, P., Baumgartner, H.J., Siegenthaler, A., Molinari, P., Laass, J., Burri, A., Jobin, A. \& Weber, J.M. (1999) Lynx management problems in the Swiss Alps. Cat News, 30, 16-18.

Breitenmoser, U., Breitenmoser-Würsten, Ch., Carbyn, L.N. \& Funk, S.M. (2001) Assessment of carnivore reintroductions. In Carnivore Conservation (eds J.L. Gittleman, S.M. Funk, D.W. Macdonald \& R.K. Wayne), pp. 241-281. Cambridge University Press, Cambridge, UK.

Breitenmoser, U. \& Haller, H. (1987) Zur Nahrungsökologie des Luchses Lynx lynx in den schweizerischen Nordalpen. Zeitschrift für Säugetierkunde, 52, 168-191.
Breitenmoser, U., Kaczensky, P., Dötterer, M., Bernhart, F., Breitenmoser-Würsten, Ch., Capt, S. \& Liberek, M. (1993a) Spatial organization and recruitment of lynx (Lynx lynx) in a reintroduced population in the Swiss Jura Mountains. Journal of Zoology, 231, 449-464.

Breitenmoser, U., Slough, B.G. \& Breitenmoser-Würsten, Ch. (1993b) Predators of cyclic prey: is the Canada lynx victim or profiteer of the snowshoe hare cycle? Oikos, 66, 551-554.

Breitenmoser-Würsten, Ch., Zimmermann, F., Ryser, A., Capt, S., Laass, J., Siegenthaler, A. \& Breitenmoser, U. (2001)

Untersuchung zur Luchspopulation in der Nordwestalpen der Schweiz 1997-2000. Kora Bericht, 9d, 1-88.

Breitenmoser-Würsten, Ch., Zimmermann, F., Stahl, P., Vandel, J.M., Molinari-Jobin, A., Molinari, P., Capt, S. \& Breitenmoser, U. (in press) Spatial and social stability of an Eurasian lynx (Lynx lynx) population - a valuation of 10 years of observation in the Jura Mountains. Wildife Biology.

Capt, S., Breitenmoser, U. \& Breitenmoser-Würsten, Ch. (1998) Monitoring the lynx population in Switzerland. In The Reintroduction of Lynx into the Alps (eds Ch. Breitenmoser-Würsten, C. Rohner \& U. Breitenmoser), pp. 105-108. Council of Europe Publishing, Strasbourg, France.

Dieckmann, U., O'Hara, B. \& Weisser, W. (1999) The evolutionary ecology of dispersal. Trends in Ecology and Evolution, 14, 88-99.

Ferreras, P., Delibes, M., Palomares, F., Fedriani, J.M., Calzada, J. \& Revilla, E. (2004) Proximate and ultimate causes of dispersal in the Iberian lynx Lynx pardinus. Behavioral Ecology, 15, 31-40.

Frank, L.G. \& Woodroffe, R.B. (2001) Behaviour of carnivores in exploited and controlled populations. In Carnivore Conservation (eds J.L. Gittleman, S.M. Funk, D.W. Macdonald \& R.K. Wayne), pp. 419-442. Cambridge University Press, Cambridge, UK.

Gossow, H. \& Honsig-Erlenburg, P. (1986) Management problems with re-introduced lynx in Austria. In Cats of the World: Biology, Conservation and Management (eds S.D. Miller \& D.D. Everett), pp. 77-83. National Wildlife Federation, Washington, DC, USA.

Hell, P. (1961) Starkes Anwachsen der Luchsbestände in der Slowakei. Zeitschrift für Säugetierkunde, 26, 57-59.

Howard, W.E. (1960) Innate and environmental dispersal of individual vertebrates. American Midland Naturalist, 63, 152-161.

Kvam, T. (1991) Reproduction in European lynx, Lynx lynx. Zeitschrift für Säugetierkunde, 56, 146-158.

Lambin, X. (1994) Natal philopatry, competition for resources, and inbreeding avoidance in Townsend's voles (Microtus townsendii). Ecology, 75, 224-235.

Lambin, X., Aars, J. \& Piertney, S. (2001) Dispersal, intraspecific competition, kin competition and kin facilitation: a review of empirical evidence. In Dispersal (eds J. Clobert, E. Danchin, A.A. Dhondt \& J.D. Nichols), pp. 110-122. Oxford University Press, New York, USA.

Lee, D.J. \& Vaughan, M.R. (2003) Dispersal movements by subadult American black bears in Virginia. Ursus, 14, 162-170.

Lubina, J.A. \& Levin, S.A. (1988) The spread of a reinvading species: range expansion in the California sea otter. American Naturalist, 131, 526-543.

Macdonald, D.W. \& Johnson, D.D.P. (2001) Dispersal in theory and practice: consequences for conservation biology. In Dispersal (eds J. Clobert, E. Danchin, A.A. Dhondt \& J.D. Nichols), pp. 358-372. Oxford University Press, New York, USA. 
Maehr, D.S., Land, E.D., Shindle, D.B., Bass, O.L. \& Hoctor, T.S. (2002) Florida panther dispersal and conservation. Biological Conservation, 106, 187-197.

McCarty, M.A. (1997) Competition and dispersal from multiple nests. Ecology, 78, 873-883.

Mech, L.D. (1987) Age, season, distance, direction, and social aspects of wolf dispersal from a Minnesota pack. In Mammalian Dispersal Patterns (eds B.D. Chepko-Sade \& Z.T. Halpin), pp. 55-74. The University of Chicago Press, Chicago, USA.

Merrill, S.B. \& Mech, L.D. (2000) Details of extensive movements by Minnesota wolves (Canis lupus). American Midland Naturalist, 144, 428-433.

Molinari-Jobin, A., Zimmermann, F., Breitenmoser, U., Breitenmoser-Würsten, Ch. \& Capt, S. (2001) Present status and distribution of the lynx in the Swiss Alps. Hystrix, 12, 17-27.

Mowat, G., Poole, K.G. \& O'Donoghue, M. (2000) Ecology of lynx in northern Canada and Alaska. In Ecology and Conservation of Lynx in the United States (eds L.F. Ruggiero, K.B. Aubry, S.W. Buskirk, G.M. Koehler, C.J. Krebs, K.S. McKelvey \& J.R. Squires), pp. 265-306. University Press of Colorado, Boulder, USA.

Ryser, A., von Wattenwyl, K., Ryser-Degiorgis, M.P., Willisch, Ch., Zimmermann, F. \& Breitenmoser, U. (2004) Luchsumsiedlung Nordostschweiz 2001-2003. Kora Bericht, 22, 1-59.

Schmidt, K., Jedrzejewski, W. \& Okarma, H. (1997) Spatial organization and social relations in the Eurasian lynx population in Bialowieza Primeval Forest, Poland. Acta Theriologica, 41, 289-312.

Stahl, P., Vandel, J.M., Herrenschmidt, V. \& Migot, P. (2001) Predation on livestock by an expanding reintroduced lynx population: long-term and spatial variability. Journal of Applied Ecology, 38, 674-687.

Stratman, M.R., Alden, C.D., Pelton, M.R. \& Sunquist, M.E. (2001) Long distance movement of a Florida black bear in the southeastern coastal plain. Ursus, 12, 55-58.

Sunde, P., Kvam, T., Moa, P., Negård, A. \& Overskaug, K. (2000) Space use by Eurasian lynxes Lynx lynx in central Norway. Acta Theriologica, 45, 507-524.

Sweanor, L.L., Logan, K.A. \& Hornocker, M.G. (2000) Cougar dispersal patterns, metapopulation dynamics, and conservation. Conservation Biology, 14, 798-808.

Swenson, J.E., Sandegren, F. \& Söderberg, A. (1998) Geographic expansion of an increasing brown bear population: evidence for presaturation dispersal. Journal of Animal Ecology, 67, 819-826.

Swenson, J.E., Wabakken, P., Sandegren, F., Bjarvall, A., Franzén, R. \& Söderberg, A. (1995) The near extinction and recovery of brown bears in Scandinavia in relation to the bear management policies of Norway and Sweden. Wildlife Biology, 1, 11-25.

Trewhella, W.J., Harris, S. \& McAllister, F.E. (1988) Dispersal distance, home-range size and population density in the red fox (Vulpes vulpes): a quantitative analysis. Journal of Applied Ecology, 25, 423-434.

Wolff, J.O. (1997) Population regulation in mammals: an evolutionary perspective. Journal of Animal Ecology, 66, 1-13.

Zar, J.H. (1984) Biostatistical Analysis, 2nd edition. Prentice-Hall, Englewood Cliffs, USA.

Zimmermann, F. (1998) Dispersion et survie des lynx (Lynx lynx) subadultes d'une population réintroduite dans la chaîne du Jura. Travail de diplôme, Université de Lausanne, Faculté des sciences. KORA Bericht, 4, 1-50. [In French with English summary]

Zimmermann, F. (2004) Conservation of the Eurasian lynx (Lynx lynx) in a fragmented landscape - habitat models, dispersal, and potential distribution. PhD thesis, University of Lausanne, Switzerland.

Zimmermann, F. \& Breitenmoser, U. (in press) Potential distribution and population size of the Eurasian lynx (Lynx $\operatorname{lynx}$ ) in the Jura Mountains and possible corridors to adjacent ranges. Wildlife Biology.

Zimmermann, F., Breitenmoser-Würsten, Ch. \& Breitenmoser, U. (2005) Natal dispersal of Eurasian lynx (Lynx lynx) in Switzerland. Journal of Zoology, 267, 381-395.

\section{Biographical sketches}

Fridolin Zimmermann is a wildlife biologist with KORA, which coordinates research projects for the conservation and management of carnivores of Switzerland. His research interests include habitat modelling, dispersal, markrecapture analyses and the transfer of scientific results to practical conservation and management measures.

Christine Breitenmoser-Würsten is a wildlife biologist who has worked on various large carnivore issues over the past 20 years, including a study of conservation and population genetics of lynx in Europe. She is currently a project coordinator at KORA.

Urs Breitenmoser has been involved in lynx conservation issues since 1981. He is a co-director of KORA and a senior researcher at the University of Bern, specializing in carnivore ecology and rabies epidemiology. 